\title{
Exploration and Practice of Quality Management of Postgraduate
}

\section{Education}

\author{
Pengjun $\mathrm{Li}^{1, \mathrm{a}}$ \\ ${ }^{1}$ College of Life Science and Technology, Jinan University, Guangzhou, Guangdong, 510632 \\ a email: pengjunsd@163.com
}

Keywords: Postgraduate Education, Quality Management, Exploration

\begin{abstract}
This paper analyzes the meaning and standard of the quality of graduate education, and expounds the hierarchical and diversified viewpoints on the quality management of postgraduate education. On the basis of summarizing the relevant characteristics of quality management of postgraduate education abroad, this paper explores the effective ways to improve the quality of postgraduate education from the perspective of quality management in the light of the practice of postgraduate education reform and development in recent years.
\end{abstract}

\section{Introduction}

Graduate education is a kind of academic education which is carried out after "undergraduate college", which belongs to the highest stage of higher education. It is the main channel for cultivating high-level innovative talents and an important force and source of knowledge innovation. In recent years, the scale of graduate education in China has grown rapidly, and the transition from quantity expansion to quality has been strengthened. In this context, how to carry out postgraduate education quality management has become an urgent need to study and solve the problem.

\section{The Meaning and Standards of Graduate Education Quality}

At present, the authoritative view of the quality of postgraduate education is the definition of "China's Degree and Graduate Education Development Strategy Report" (2002-2010): the quality of graduate education refers to the ability of the graduate education system to provide services to meet all the needs of the community sum. The survival and development of graduate education has always been around the needs of the state, the employing units and students. The products offered by the postgraduates mainly include: high-level specialized talents of all levels, types and disciplines of postgraduates to provide all kinds of scientific and technological achievements and their related services. Its "product" is different from the general product and it is through the artificial carrier of the knowledge and skills and professional and technical level, through the efforts of educators, and ultimately the country and the development of society to contribute ${ }^{[1]}$.

Graduate education is through the community to provide educational services and access to social identity, so to meet the needs of the community is to test the quality of graduate education standards. Due to the continuous development of society, the needs of society are diverse, multi-level. From the perspective of quality management to analyze, usually a product quality standards cannot be lower than the user's needs, but also should not exceed the needs of users, because the quality of the product costs increase, resulting in price, and therefore should be in product quality and cost Between the balance. Similarly, the quality of graduate education there is 
such a problem, if the quality standards are too high, the cost will be high, but will reduce the social benefits, will bring heavy burden on the school; if the number of one-sided pursuit of the size, it will be at the expense of the quality of education at the expense of social needs cannot meet ${ }^{[2]}$.

Therefore, we should not generally improve the quality of graduate education, but to distinguish between different levels, different types of school graduate education, put forward in line with their own characteristics and practical needs of the quality standards.

\section{The Characteristics of Foreign Graduate Education Quality Management}

The Quality of Graduate Education Should Base on Internal Security. Foreign developed countries attach great importance to the selection of graduate students, colleges and universities to attract outstanding students often exist in the fierce competition. Mentors and professors play a leading role in the selection of graduate students. American higher education in the internal quality management on the implementation of strict "elimination system", that is strict output quality, every year some students failed to obtain a degree, brand-name university out of the higher rate.

Attach Importance to the Role of Social Oversight Mechanisms. Developed countries in the quality of management are attached to the effective use of external forces to play an effective intervention on the quality of postgraduate education. In order to increase the transparency of quality control, the UK has adopted a way for the community to participate directly in school management. British higher education has a strong external system, including the University Fund Committee, the National Degrees Committee, the Higher Education Quality Association, Higher Education Quality Assurance Agency, the Royal Detachment Division and other institutions. The quality control of postgraduate education in the United States is mainly carried out by non-governmental, nonprofit professional associations (such as the American Graduate School Association and the American Association of Universities and their Associated Graduate Schools) and its accreditation bodies and the media The prestigious annual National Graduate Education Assessment conducted by the American Journalism and World Report weekly, academic rankings for best graduate and professional colleges, their university rankings, classification results or assessment results even become federations Government and social organizations to provide funding for an important basis ${ }^{[3]}$.

Attach Importance to the Cultivation of Postgraduate Scientific Research Ability and Practical Ability. American universities believe that postgraduate education only imparts professional and professional knowledge is not enough, professional settings and training objectives to be able to closely combine the urgent needs of production and technology development, training to meet the needs of the community of senior personnel. Therefore, professional settings mainly to market-oriented and students provide professional knowledge framework, the basic skills and principles for the purpose, with particular emphasis on the practical ability of students to develop.

Pay Attention to the Construction of High Level Mentor Team. In foreign countries, graduate education has become an important channel to absorb the world's top talent. American universities on the one hand through the graduate education to increase the intensity of domestic personnel training, on the other hand through high quality and efficient graduate education from the international scope to attract outstanding talent. Some of the prestigious universities in the United States can cultivate world-class experts and scholars, which is inseparable from the fact that they absorb many scientists, scholars and Nobel prizes to enrich their faculty ${ }^{[4]}$.

It is of great significance to learn from and learn from the experience of quality management of postgraduate education abroad. It is of great significance to improve the level of education and management of postgraduates in China to build world - class universities and first - class disciplines 
and cultivate world - class talents.

\section{The Exploration and Practice of Postgraduate Education Quality Management}

The quality management of postgraduate education is reflected in the relationship between the quality of graduate education and the social environment such as politics, economy, science and technology, culture and so on. The development of the elements of the social environment will inevitably lead to changes in the quality management of graduate education, the scale of graduate education, structure, quality management and other active adaptation and even lead the needs of social and economic development; the other hand, under the established social conditions, postgraduate education quality management should take the initiative to follow the objective law of educational activities and the logic of its own discipline meet the needs of the individuals of the educated individual in accordance with the principle of unity of law and purpose.

Deepen the Graduate Enrollment System Reform and Keep a Good Entrance. Actively explore the selection mechanism of graduate students' enrollment, establish and adapt to the training objectives, is conducive to top-notch innovative talents and high-level application talents stand out from the scientific and fair diversity of enrollment system, and comprehensively promote the graduate enrollment system reform.

First, to improve the quality of talent selection as the goal, the establishment of a sound ability, knowledge and quality of the assessment system, to further improve the selection of innovative talent mechanism; Second, the establishment of performance evaluation as the core of the graduate enrollment plan dynamic adjustment mechanism; Strengthen the supervision mechanism, strengthen the process management to ensure that the work of scientific and standardized enrollment, fair and impartial.

Promote Postgraduate Training Management Reform and Keep a Good Training. With the overall quality of the concept as a guide, and gradually promote the reform of postgraduate training and management. Comprehensive quality concept to a comprehensive and development point of view to evaluate the quality of graduate education, in addition to examine the academic standards, more to analyze the professional settings of graduate education, training types and models to adapt to the social needs of high-level talent, as well as the cultivation of graduate students to meet the needs of this degree ${ }^{[5]}$.

Master graduate is the pilot of our country's degree education system, at the beginning of the implementation of it as an independent unit, including the doctoral education similar to the training model, link requirements and a relatively long training cycle. However, with the continuous improvement of the graduate education system in our country, the ability of cultivating doctoral students has been greatly improved and the scale has been expanded rapidly. The master's degree education still follows the irrationality of the doctoral students' training mode. This model not only takes up a lot of our limited educational resources, limits the development of high level graduate education in our country, but also makes the talent education cycle too long and cannot be in line with the international education model of the master's degree and the transitional degree.

Construct the cross-disciplinary innovative talent training platform, the establishment of interdisciplinary graduate training management model. In order to promote the organizational innovation and management innovation, the school should rely on key disciplines, innovation team and so set up graduate training platform. In the platform covered by the national, provincial and ministerial level key disciplines, the establishment and implementation of scientific research-led mentor responsibility system, to take the tilt policy, the implementation of reward and punishment system. To attract outstanding students, improve the quality of postgraduate training. 
Improve the Quality Assurance System and Keep the Good Export Customs. To further strengthen the graduate teacher's sense of responsibility and mentor responsibility system to strengthen the graduate students in the subject research, degree thesis writing, dissertation review, defense and other important aspects of the process of management and quality control; the implementation of an anonymous review to improve the potential of scientific and technological innovation of postgraduates to improve the degree of attention and quality awareness of mentors and graduate students, and to constantly improve the quality assurance system of degree thesis.

Improve the Evaluation Mechanism of Graduate Education and Keep Good Supervision. The basic purpose of the postgraduate education assessment is to evaluate the behavior and activities of postgraduate education, to examine its use of educational resources and achievements, to strengthen the school's macro guidance and management of graduate education. Through the evaluation, we can improve the educational performance of graduate students and improve the operation efficiency of each organization. We can optimize the allocation of resources, determine the distribution of educational resources between various professions and disciplines, further clarify the corresponding responsibilities and establish the corresponding restraint mechanism.

The specific contents of the evaluation include: the quality assessment of graduate students and the evaluation of teaching quality, the quality evaluation of degree thesis, the evaluation of mentor ability and the evaluation of new level of discipline construction. In carrying out the specific assessment work at the same time, actively explore the construction of scientific evaluation index system, the school development of a forward-looking, long-term planning, the assessment as the school's long-term sustainable development needs.

\section{Acknowledgements}

Fund Project: Guangdong Province degree and graduate education reform research project" Graduate student training research based on the sharing of resources "(No. 2014JGXM-MS06), Guangdong Province Department of education Seedling project" A research of graduate education development quality system "(No. WYM10078).

\section{References}

[1] Qin Huimin, degree and graduate education dictionary [M]. Beijing Institute of Technology Press, 1994.

[2] Xiao Min, the establishment of three-dimensional quality assurance system for graduate education [J]. Degree and Graduate Education, 2003 (6).

[3] Chen Qibiao, a comparative study of postgraduate education assessment in China and the United States [J]. Comparative Education Research, 2001 (2).

[4] Wang Yanru, China's graduate education quality management optimization research [D]. Lanzhou, Lanzhou University master's thesis, 2007.

[5] Zhang Minxian, overall quality and multiple training objectives - on the graduate student system reform [J]. Degree and graduate education, 2006 (8). 